\title{
Palaeotemperature reconstruction from noble gases in ground water taking into account equilibration with entrapped air
}

W. Aeschbach-Hertig* ${ }^{*}$, F. Peeters*, U. Beyerle* \& R. KIpfer*

* Department of Water Resources and Drinking Water, Swiss Federal Institute of Environmental Science and Technology (EAWAG), CH-8600 Dubendorf, Switzerland

$\dagger$ Environmental Physics, $\neq$ Isotope Geology, Swiss Federal Institute of Technology (ETH), CH-8902 Zurich, Switzerland

Noble-gas concentrations in ground water have been used as a proxy for past air temperatures ${ }^{1-7}$, but the accuracy of this approach has been limited by the existence of a temperatureindependent component of the noble gases in ground water, termed 'excess air', whose origin and composition is poorly understood $^{7-9}$. In particular, the evidence from noble gases in a Brazilian aquifer for a cooling of more than $5^{\circ} \mathrm{C}$ in tropical America during the Last Glacial Maximum ${ }^{4}$ has been called into question'. Here we propose a model for dissolved gases in ground water, which describes the formation of excess air by equilibration of ground water with entrapped air in quasisaturated soils $s^{10-12}$. Our model predicts previously unexplained noble-gas data sets, including the concentration of atmospheric helium, and yields consistent results for the non-atmospheric helium isotopes that are used for dating ground water. Using this model of excess air, we re-evaluate the use of noble gases from ground water for reconstructing past temperatures. Our results corroborate the inferred cooling in Brazil during the Last Glacial Maximum ${ }^{4}$, and indicate that even larger cooling took place at mid-latitudes.

Noble gases in ground water consist of three components: (1) dissolved air at solubility equilibrium, (2) certain isotopes from radioactive decay ${ }^{13}$, and (3) "excess air ${ }^{m 8}$. The temperature dependence of the first component has been used to infer recharge temperatures of ground water in order to reconstruct palaeotemperatures ${ }^{1-7}$. The second component is of importance for $\mathrm{He}\left({ }^{3} \mathrm{He}\right.$ from ${ }^{3} \mathrm{H},{ }^{4} \mathrm{He}$ from U/Th), and has been used extensively for groundwater dating ${ }^{14-19}$. Little is known about the origin and composition of the third component, although excess air may contain information about the environmental conditions pertaining during infiltration ${ }^{7,20-22}$. An understanding of the excess-air phenomenon is needed for the reliable calculation of noble-gas temperatures (NGTs) and groundwater ages.

Usually it is assumed that excess air is formed by total dissolution

\begin{tabular}{|c|c|c|c|c|c|c|c|}
\hline \multirow[b]{2}{*}{ Data set } & \multirow[b]{2}{*}{$N$} & \multicolumn{2}{|c|}{ TD model } & \multicolumn{2}{|c|}{ PR model } & \multicolumn{2}{|c|}{ CE model } \\
\hline & & $x^{2}$ & $P$ & $x^{2}$ & P & $x^{2}$ & P \\
\hline Brazil & 20 & 626.4 & $<10^{14}$ & 71.8 & $9 \times 10^{8}$ & 35.8 & 0.016 \\
\hline Oman & 9 & 153.0 & $<10^{14}$ & 55.2 & $1 \times 10^{8}$ & 20.4 & 0.016 \\
\hline Maryland & 20 & 246.8 & $<10^{14}$ & 44.5 & 0.001 & 18.2 & 0.574 \\
\hline Belgium & 28 & 303.6 & $<10^{14}$ & 55.7 & 0.001 & 12.8 & 0.994 \\
\hline Belgium $\mathrm{He}^{\star}$ & 28 & 358.6 & $<10^{14}$ & 191.5 & $1 \times 10^{14}$ & 34.2 & 0.990 \\
\hline \multicolumn{8}{|c|}{$\begin{array}{l}N \text { is the number of samples of each data set. } \chi^{2} \text { is the sum of the weighted squared deviations } \\
\text { between modelled and measured noble-gas concentrations, summed over all samples of a data } \\
\text { set }{ }^{223} \text {. The expected value of } \chi^{2} \text { is equal to the number of degrees of freedom, which is the number } \\
\text { of fitted concentrations ( } 4 N \text {, with He } 5 N \text { ) minus the number of free model parameters }\left(2 N\left(T, A_{d}\right) \text { for }\right. \\
\text { the TD model, } 3 N\left(T, A_{d}, R \text { or } T, A_{e}, F \text { otherwise). } P \text { is the probability that } \chi^{2} \text { exceeds the observed }\right. \\
\text { value. Models with } P<0.01 \text { are rejected. }\end{array}$} \\
\hline
\end{tabular}




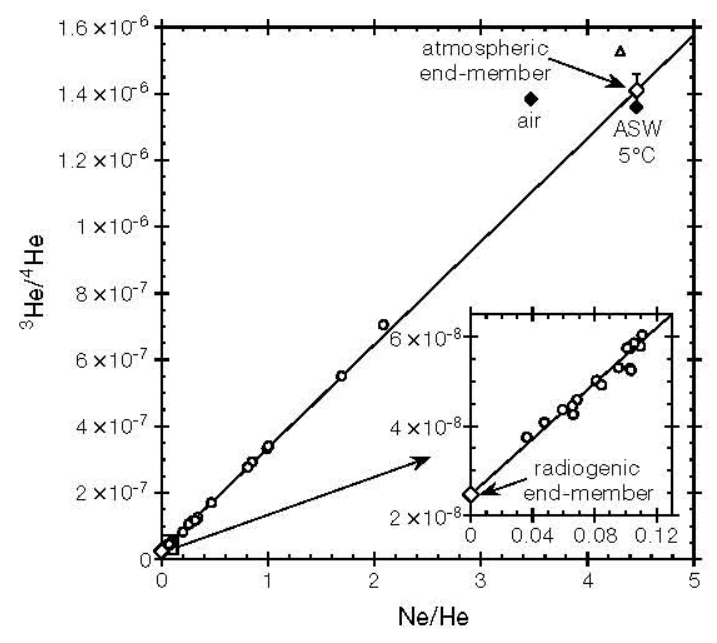

Figure $1 \mathrm{He}$ isotope ratio versus Ne/He elemental ratio of samples from Belgium. The data define a mixing line between a radiogenic and an atmospheric end-member. The linear regression was calculated by a least-squares fit weighted with both $x$ and $y$ errors (errors are similar to the size of the symbols). One sample (triangle) from a shallow well in the

of small air bubbles trapped in soil pores ${ }^{2,3,5,8}$. In this total dissolution (TD) model, the concentrations of dissolved atmospheric gases $\operatorname{are}^{23}:$

$$
C_{i}\left(T, S, P, A_{\mathrm{d}}\right)=C_{i}^{*}(T, S, P)+A_{\mathrm{d}} z_{i}
$$

where $C_{i}^{*}(T, S, P)$ are the moist-air solubility equilibrium concentrations as functions of temperature, salinity, and atmospheric pressure, $A_{\mathrm{d}}$ is the concentration of totally dissolved dry air, and $z_{i}$ are the volume fractions of the individual gases in dry air. However, because the TD model does not yield consistent NGTs for the noblegas record from Brazil, a model of excess-air fractionation by partial diffusive re-equilibration (PR model) was introduced ${ }^{4}$, which may be written as $^{23}$ :

$$
C_{i}\left(T, S, P, A_{\mathrm{d}}, R\right)=C_{i}^{*}(T, S, P)+A_{\mathrm{d}} z_{i} \mathrm{e}^{-R_{D_{\mathrm{N}}}}
$$

where $R$ is a parameter describing the degree of re-equilibration and $D_{i}$ are the molecular diffusion coefficients. Yet, even the PR model does not provide an adequate description of the Brazilian noble-gas data ${ }^{9}$.

Here we propose a new model explaining excess air as the result of equilibration of ground water with persistent entrapped air. The occurrence of air entrapment during groundwater infiltration is well known ${ }^{10-12}$, but has never been quantitatively linked to the phenomenon of excess air. The basic assumption of our model is that solubility equilibrium is attained in a closed system of initially air-saturated water and a finite volume of entrapped air under a

\begin{tabular}{|c|c|c|c|c|}
\hline Data set & $A_{e}$ & v & $q$ & $F$ \\
\hline Brazil & $0.017 \pm 0.005$ & $0.53 \pm 0.19$ & $1.56 \pm 0.29$ & $0.37 \pm 0.17$ \\
\hline Oman & $0.025 \pm 0.020$ & $0.78 \pm 0.12$ & $1.31 \pm 0.19$ & $0.61 \pm 0.14$ \\
\hline Maryland & $0.049 \pm 0.059$ & $0.88 \pm 0.07$ & $1.16 \pm 0.04$ & $0.76 \pm 0.06$ \\
\hline Belgium & $0.083 \pm 0.074$ & $0.91 \pm 0.08$ & $1.16 \pm 0.08$ & $0.79 \pm 0.09$ \\
\hline Expected* & $0.02-0.18$ & $\sim 0.9$ & $\sim 1.2$ & $\sim 0.75$ \\
\hline
\end{tabular}

Table 2 Values of excess-air parameters obtained from fits of the CE model $A_{\mathrm{e}}$ is given in $\mathrm{cm}^{3}$ STP $\mathrm{g}^{-1}$; the other parameters are dimensionless. Mean values and standard deviations of the results from the individual samples are given.

"Expected values were derived from empirical field data as follows. $A_{\mathrm{e}}$ : entrapped air was found to occupy between $2 \%$ and $15 \%$ of the pore space (corresponding to $2-18 \%$ of water volume) during groundwater infiltration $n^{11}$. v: Typical concentrations of dissolved excess air are of the onder of 0.001 to $0.01 \mathrm{~cm}^{3}$ STP $\mathrm{g}^{-1}(10-100 \% \Delta \mathrm{Ne})^{3-5.723}$, indicating dissolution of only about $10 \%$ of $A_{e}$, and hence corresponaing tov-values of about 0.9.9: air entrapment occurs in the uppermost metres of hydrostatic overload F: from $F=v / q$. recharge area appears to be affected by ${ }^{3} \mathrm{He}$ from the decay of bomb tritium, and was thus excluded from the fit. The point for air-saturated water (ASW) is shown for the representative temperature of $5^{\circ} \mathrm{C}$

constant hydrostatic pressure. The equations of this closed-system equilibration (CE) model are:

$$
C_{i}\left(T, S, P, A_{\mathrm{e}}, F\right)=C_{i}^{*}(T, S, P)+\frac{(1-F) A_{\mathrm{e}} z_{i}}{1+F A_{\mathrm{e}} z_{i} / C_{i}^{*}}
$$

where $A_{\mathrm{e}}$ is the initial amount of entrapped air per unit mass of water and $F$ is the fractionation parameter (Methods). Note that $A_{\mathrm{e}}$ (entrapped air) is the same as $A_{\mathrm{d}}$ (dissolved air) only in the case of total dissolution. $F$ is the ratio of two parameters with a clear physical meaning: $v$, the ratio of the entrapped gas volumes in the final and initial state, and $q$, the ratio of the dry gas pressure in the trapped gas to that in the free atmosphere. The values of $v$ and $q$ can be calculated from $F=v / q$ and $A_{\mathrm{e}}$, using the condition that the sum of all partial pressures in the trapped volume equals the total pressure. Equation (3) describes all possible cases between no excess air ( $F=v=q=1)$, pure excess air $(F=0, v=0$ or $q$ infinite), and a pure pressure effect, that is, equilibration with the atmosphere at increased pressure $\left(v=1, q>1, F=1 / q<1, A_{\mathrm{e}}\right.$ infinite). Thus, it is a very general description of the concentrations of dissolved gases in ground water.

Equations (1) to (3) describe the concentrations of $\mathrm{Ne}, \mathrm{Ar}, \mathrm{Kr}$ and $\mathrm{Xe}$ (He is usually affected by non-atmospheric sources) with up to five parameters. In practice, $S$ and $P$ are usually known $(S \approx 0$ for meteoric water, and $P$ can be calculated from the altitude of the recharge area). The remaining unknown parameters have traditionally been determined by iteration ${ }^{3,4,7}$. Recently, weighted leastsquares techniques to invert the model equations have been developed, enabling quantitative assessment of the ability of different conceptual models to explain the observations ${ }^{9,23}$.

We checked the practical applicability of the models by fitting them to two noble-gas data sets from tropical regions, northeastern Brazil $^{4}$ and Oman ${ }^{6}$, and two from temperate regions, Maryland (USA) ${ }^{24}$ and Belgium. The goodness of fit was quantified by applying the $\chi^{2}$ test to the ensemble of the samples of each data set $^{9,23}$ (Table 1). Although the PR model performs far better than the TD model, it does not describe the observed noble-gas concentrations within their experimental uncertainty. In all cases, only the CE model yields an acceptable description of the data. The physical plausibility of the CE model can be checked by comparing the results obtained for its physically interpretable parameters with empirical findings on entrapped air and excess air (Table 2). The 
Table 3 Model dependence of non-atmospheric He components and corresponding ages

\begin{tabular}{|c|c|c|c|c|c|}
\hline \multirow[b]{2}{*}{ Model } & \multicolumn{2}{|c|}{ Maryland: 4 young samples } & \multicolumn{3}{|c|}{ Switzerland: 5 fractionated samples } \\
\hline & $\left(10^{8}{ }^{4} \mathrm{~cm}^{3} \mathrm{STPg}{ }^{1}\right)$ & $\begin{array}{c}{ }^{4} \mathrm{He} \text { age } \\
(y r)\end{array}$ & $\left(10^{9}{ }^{4} \mathrm{~cm}^{3} \mathrm{Hed}_{\mathrm{rad}}{ }^{4}\right)$ & 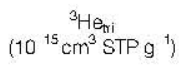 & $\begin{array}{c}{ }^{3} \mathrm{H}-{ }^{3} \mathrm{He} \text { age } \\
\left(y r^{\prime}\right)\end{array}$ \\
\hline TD model & $-1.0 \pm 0.8$ & $-630 \pm 490$ & $-0.5 \pm 0.8$ & $-0.1 \pm 1.4$ & $0.0 \pm 0.4$ \\
\hline PR model & $7.8 \pm 2.3$ & $4,700 \pm 1,400$ & $5.9 \pm 1.2$ & $9.4 \pm 2.0$ & $2.4 \pm 0.5$ \\
\hline CE model & $0.3 \pm 0.5$ & $210 \pm 290$ & $0.6 \pm 0.9$ & $1.4 \pm 1.4$ & $0.4 \pm 0.4$ \\
\hline Expected* & $<0.08$ & $<50$ & $0.8 \pm 0.4$ & $3.1 \pm 1.3$ & $0.8 \pm 0.3$ \\
\hline
\end{tabular}

Mean values and standard deviations of the results from the individual samples are given.

"Expected values were derived as follows. Maryland: the 4 samples discussed here are from shallow wells in the recharge area and must be less than $50 \mathrm{yr}$ old according to ${ }^{3} \mathrm{H}$ and ${ }^{3} \mathrm{He}$ data. Conversion between ${ }^{4} \mathrm{He}_{\mathrm{r} \text { rd }}$ and ages is done using the in situ production rate of $1.6 \times 10^{-12} \mathrm{~cm}^{3} \mathrm{STP}^{-1} \mathrm{yr}^{-1}$, derived from $\mathrm{U}$ and Th analyses on sediment samples and supported by ${ }^{14} \mathrm{C}$ ages $\mathrm{s}^{24}$. Switzerland: the 5 samples discussed here, all from one particular sampling date, are the only ones with fractionated excess air out of a data set of 48 samples ${ }^{17,23}$. Expected results were estimated based on 10 samples from the same boreholes but other sampling dates.

data sets from Maryland and Belgium yield values within the expected range. The two tropical records yield higher values of $q$ and lower values of $A_{\mathrm{e}}$ and $v$. This finding may reflect actual differences in the infiltration regime, for example, larger watertable fluctuations (higher $q$ ) in the tropical aquifers.

The conclusion that only the $\mathrm{CE}$ model provides a realistic description of the data is further supported by an analysis of the usually neglected He data. Because of its low solubility and high diffusivity, He reacts most sensitively to excess air and to diffusive fractionation. However, most palaeogroundwaters contain large excesses of non-atmospheric, usually radiogenic, He. Atmospheric $\left(\mathrm{He}_{\mathrm{atm}}\right)$ and radiogenic $\left(\mathrm{He}_{\mathrm{rad}}\right) \mathrm{He}$ components may be separated based on their very different ${ }^{3} \mathrm{He} /{ }^{4} \mathrm{He}$ ratios ${ }^{25}$. Our data from Belgium define a two-component mixing line between a radiogenic and an atmospheric end-member (Fig. 1). Based on the position along this line, each sample was split into its components (Methods).

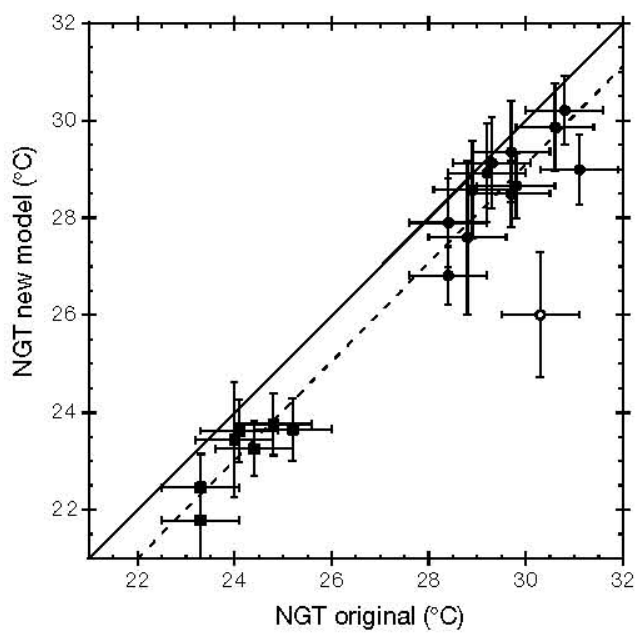

Figure 2 Comparison of new and original noble gas temperatures (NGTS) from Brazil. In the original publication ${ }^{4}$, NGTs were calculated using an iterative technique to correct for fractionated excess air according to the PR model. We re-evaluated NGTS by inversion of the new CE model for fractionated excess air. Symbols reflect the clusters of samples identified in the original work: filled circles correspond to high temperatures and $10{ }^{14} \mathrm{C}$ ages, filled squares to lower temperatures and higher ages, and the open circle refers to a special sample (no. 17) which for several reasons was omitted in calculating the glacialinterglacial temperature difference ${ }^{4}$. The regression line (dashed) through the data (excluding sample 17) is practically parallel to the $1: 1$ line (solid), and indicates that the new NGTs are on average $1^{\circ} \mathrm{C}$ lower than the original values. The mean new NGT of the warm cluster is $28.7+0.3^{\circ} \mathrm{C}$ (compared to $29.6^{\circ} \mathrm{C}$ in the original evaluation) in good agreement with the mean local ground temperature of $29.1^{\circ} \mathrm{C}$. The cool cluster yields a mean NGT of $23.1+0.3^{\circ} \mathrm{C}$ (original value $24.2^{\circ} \mathrm{C}$ ). We note that temperature difference between warm and cold clusters remains practically unchanged $\left(5.6+0.4^{\circ} \mathrm{C}\right)$.
The calculated $\mathrm{He}_{\mathrm{atm}}$ was then used as a fifth, excess air sensitive, constraint in the inversion of equations (1) to (3). With this additional constraint, the CE model still provides a good fit, whereas the PR model becomes clearly unacceptable (Table 1 ).

The predictions of the PR and CE models for $\mathrm{He}_{\mathrm{atm}}$ differ strongly due to high diffusive $\mathrm{He}$ loss in the PR model. This fact has consequences for groundwater dating based on the accumulation of radiogenic ${ }^{4} \mathrm{He}_{\mathrm{rad}}$ and tritiogenic ${ }^{3} \mathrm{He}_{\text {tri: }}$. These $\mathrm{He}$ components are best determined by measuring all noble gases, and using the parameters derived from the inverse modelling of the heavier noble gases to calculate $\mathrm{He}_{\mathrm{atm}}$. We used this approach to calculate ${ }^{4} \mathrm{He}_{\mathrm{rad}}$ in samples from the recharge area of the coastal aquifer in Maryland ${ }^{24}$ as well as ${ }^{4} \mathrm{He}_{\mathrm{rad}}$ and ${ }^{3} \mathrm{He}_{\text {tri }}$ in samples from a shallow alluvial aquifer in Switzerland ${ }^{17,23}$. In both examples, we can estimate the expected results (Table 3). The TD model implies obviously inconsistent negative values of the non-atmospheric $\mathrm{He}$ components and corresponding ages. The PR model yields unrealistically high ages. Only the results obtained with the CE model are in accordance with expectations.

For dating with $\mathrm{He}$ isotopes, usually only $\mathrm{Ne}$ is measured to calculate $\mathrm{He}_{\mathrm{atm}}$, based on the assumption that excess air has the atmospheric $\mathrm{He} / \mathrm{Ne}$ ratio of 0.288 (TD model) $^{14-17}$. As in our examples, this assumption sometimes leads to negative ages ${ }^{16,17}$. This inconsistency can be resolved by assuming fractionated excess air with a lower $\mathrm{He} / \mathrm{Ne}$ ratio. In contrast to the PR model, the CE model predicts a lower limit of the excess air $\mathrm{He} / \mathrm{Ne}$ ratio, given by the value for equilibrated water $(0.22$ to 0.25 , depending on temperature). This value can be used to define an upper boundary for non-atmospheric He components and related ages. Our results highlight the advantage of combining analyses of He isotopes and atmospheric noble gases. He data may be useful to identify excess air fractionation and hence to obtain more reliable NGTs. Conversely, atmospheric noble-gas data provide a firm basis for the calculation of the non-atmospheric ${ }^{4} \mathrm{He}$ and ${ }^{3} \mathrm{He}$ components needed for dating.

The most important implications of our excess air model concern the reliability of noble-gas palaeoclimate records, particularly with regard to the controversial issue of tropical temperatures during the Last Glacial Maximum. The discrepancy between weak glacial cooling $\left(\leq 2^{\circ} \mathrm{C}\right)$ indicated by most oceanic palaeoclimate proxies $^{26,27}$, and a strong temperature change $\left(\sim 5^{\circ} \mathrm{C}\right)$ indicated by continental records $s^{4,28,29}$, is still not entirely explained.

The reliability of the important evidence for a large continental cooling provided by the Brazilian noble-gas study depends on an appropriate understanding of excess air. The original interpretation was based on the PR model ${ }^{4}$, which is inconsistent with the data ${ }^{9}$ (Table 1). Applying the CE model and the inverse fitting procedure $^{23}$, we obtain consistent new NGTs that are systematically lower than the original values by about $1^{\circ} \mathrm{C}$ (Fig. 2). The data form two clusters, one corresponding to high temperatures and low ${ }^{14} \mathrm{C}$ ages, the other to lower temperatures and higher ages. The temperature difference between the clusters is $5.6 \pm 0.4^{\circ} \mathrm{C}$, indistin- 
guishable from the original result of $5.4 \pm 0.6^{\circ} \mathrm{C}$. Our internally consistent and mathematically rigorous analysis of the data reinforces the conclusion of $\mathrm{a} \sim 5^{\circ} \mathrm{C}$ glacial-interglacial temperature difference in tropical Brazil. The hypothesis of a large tropical cooling is further supported by recent noble-gas records indicating a glacial cooling of $6.5^{\circ} \mathrm{C}$ in $\mathrm{Oman}^{6}$ and $5.3^{\circ} \mathrm{C}$ in Namibia ${ }^{22}$. Whereas the Oman data could only be interpreted with the new CE model, the results from Namibia were based on the PR model and may need to be re-evaluated.

The CE model is crucial for a consistent interpretation not only of the tropical noble-gas records, but also those from Maryland and Belgium (Table 1). NGTs calculated with the CE model suggest an even larger $\left(7-9^{\circ} \mathrm{C}\right)$ glacial cooling for these mid-latitude records. The original interpretation of other noble-gas data sets from temperate regions was based on the TD model and has also been questioned ${ }^{9}$. We expect that a re-evaluation of these data will primarily affect the individual NGTs rather than the reconstructed glacial-interglacial temperature difference, as exemplified by the Brazilian record. The inverse technique of calculating $\mathrm{NGTs}^{9,23}$ and the view of excess air described here provide a mathematically and physically sound theoretical foundation for the noble-gas palaeothermometer. The resulting reliable NGTs may be used to calibrate the ${ }^{18} \mathrm{O}$ palaeothermometer by simultaneous analysis of noble gases and ${ }^{18} \mathrm{O}$ in aquifers ${ }^{5}$.

Finally, our model provides a link between investigations of dissolved gases in ground water and the study of air entrapment in quasi-saturated soils. We are currently investigating relationships between entrapped air, excess air, fractionation, and infiltration conditions in laboratory and field studies. Eventually, excess air may provide information just as important as that derived from the other noble-gas components in ground water.

\section{Methods}

\section{Model derivation}

According to Henry's law, at solubility equilibrium the gas concentrations $C_{i}$ in solution are proportional to the partial pressures $p_{i}$ in the gas phase:

$$
p_{i}=H_{i}(T, S) C_{i}
$$

where $H_{i}(T, S)$ is the Henry coefficient, depending on temperature $T$ and salinity $S$.

We describe a closed system consisting of a water volume $V_{w}$ and an initial trapped air volume $V_{\mathrm{g}}^{\mathrm{g}}$ under a constant total pressure $P_{\mathrm{g}}=P+P_{\mathrm{h}}$, where $P$ is the atmospheric and $P_{\mathrm{h}}$ the hydrostatic pressure. In the initial state, the dissolved gas concentrations are in atmospheric solubility equilibrium ${ }^{23}$

$$
C_{i}^{*}(T, S, P)=\frac{p_{i}^{a t m}}{H_{i}(T, S)}=\frac{(P-e(T)) z_{i}}{H_{i}(T, S)}
$$

where $e(T)$ is the saturation water vapour pressure and $z_{i}$ are the volume fractions in dry air. The volume at STP of dry entrapped air per unit mass of water is:

$$
A_{e}=\frac{V_{g}}{\rho(T, S) V_{w}} \frac{\left(P_{g}-e(T)\right)}{P_{0}}
$$

where $\rho(T, S)$ is the water density, and $P_{0}$ is the standard pressure ( $1 \mathrm{~atm}$ ).

In the final state, a gas volume $V_{g}$ remains and equilibrium is achieved, that is, all gases partition between $V_{g}$ and $V_{w}$ according to Henry's law, equation (4). In a closed system, the total gas amounts must be conserved, that is, the sum of the number of moles of each gas in the water and the gas phase is equal in the initial and the final state.

$$
n_{i, w}^{0}+n_{i, s}^{0}=n_{i, w}+n_{i, s}
$$

Inserting equations (4) to (6) into (7) and using the ideal-gas law leads to equations that describe the concentrations of dissolved gases in the water in the final state

$$
C_{i}=\left(C_{i}^{*}+A_{e} z_{i}\right)\left(1+\frac{V_{g}}{V_{w}} \frac{(P-e) z_{i}}{\rho P_{o} C_{i}^{*}}\right)^{-1}
$$

where $C_{i}^{*}=C_{i}^{*}(T, S, P)$ are the moist air solubility equilibrium concentrations as in equation (5). By defining $v=V_{\mathrm{g}} / V_{\mathrm{g}}^{\circ}, q=\left(P_{\mathrm{g}}-e\right) /(P-e)$, and $F=v / q$, we finally arrive at the model equations (3).

\section{Separation of He components}

Because the radiogenic $\mathrm{He}$ component $\left(\mathrm{He}_{\mathrm{rad}}\right)$ is highly variable and can be overwhel- mingly large, the measured concentrations of ${ }^{4} \mathrm{He}$ or total $\mathrm{He}\left(\mathrm{He}_{\text {meas }}\right)$ provide no information on the atmospheric $\mathrm{He}$ component ( $\mathrm{He}_{\mathrm{e}}$ ) to be used to invert the model equations (1) to (3). However, because the typical radiogenic ${ }^{3} \mathrm{He} /{ }^{4} \mathrm{He}$ ratio $\left(R_{\mathrm{rad}} \approx 2 \times 10^{8}\right)$ is two orders of magnitude smaller than that of the atmospheric sub components (air: $R_{2}=1.384 \times 10^{6}$, air-saturated water: $R_{\mathrm{aw}} \approx 0.983 R_{\mathrm{a}}$; ref. 30), the radiogenic component is much less dominant for ${ }^{3} \mathrm{He}$. If $\mathrm{He}_{\text {meas }}$ in a given aquifer results from a simple two-component mixture of $\mathrm{He}_{\text {atm }}$ and $\mathrm{He}_{\mathrm{rad}}$, both with uniform isotopic compositions $\mathrm{R}_{\mathrm{atm}}$ and $\mathrm{R}_{\mathrm{rad}}$, measuring both $\mathrm{He}$ isotopes yields information on $\mathrm{He}_{\text {atrm. }}$ To extract this information, we have to use the ensemble of the data set.

A plot of the measured ${ }^{3} \mathrm{He} /{ }^{4} \mathrm{He}$ isotope ratio versus the $\mathrm{Ne} / \mathrm{He}$ elemental ratio can serve both as a check of the two-component mixing hypothesis as well as to define the isotopic composition of the end-members. The excellent linear correlation in our example from Belgium (Fig. 1) confirms that each sample is essentially a mixture of two end-members. The intercept of the regression line (calculated by a least-squares fit weighted with both $x$ and $y$ errors $)$ at $\mathrm{Ne} / \mathrm{He}=0$ defines $R_{\mathrm{rad}}=(2.47 \pm 0.20) \times 10^{8}$, typical for radiogenic $\mathrm{He}$. The atmospheric end-member must lie on the regression line in the vicinity of the point for air-saturated water (ASW). Addition of ${ }^{3} \mathrm{He}$ from the decay of natural (pre-bomb) tritium shifts the end-member slightly upwards. We take the ${ }^{3} \mathrm{He} /{ }^{4} \mathrm{He}$ ratio defined by the regression line at the $\mathrm{Ne} / \mathrm{He}$ value of the ASW point as the best estimate for $R_{\text {atm }}$, with an uncertainty large enough to include $R_{\text {swo }}$ yielding $R_{\text {tam }}=(1.41 \pm 0.05) \times 10^{6}$

The measured He isotope ratios $\left(R_{\text {meas }}\right)$ reflect the mixing ratios of the two endmembers. Using $R_{\mathrm{atm}}$ and $R_{\mathrm{rad}}$ defined from the entire data set, the contribution of $\mathrm{He}_{\mathrm{atm}}$ to each individual sample can be calculated:

$$
\mathrm{He}_{\mathrm{atm}}=\mathrm{He}_{\text {reas }} \frac{\left(R_{\text {meas }}-R_{\mathrm{rad}}\right)}{\left(R_{\mathrm{amm}}-R_{\mathrm{rad}}\right)}
$$

In the Belgian data set, the uncertainty of the calculated $\mathrm{He}_{\text {atm }}$ ranges from $4 \%$ (due to the uncertainty in $R_{\text {atm }}$ ) up to $15 \%$ for the samples with the highest $\mathrm{He}_{\text {rad }}$. Even this limited precision is however sufficient to distinguish between the PR and CE models, because their predictions for $\mathrm{He}_{\mathrm{atm}}$ are very different (Table 1 ).

Received 14 October 1999; accepted 18 May 2000.

1. Mazor, E. Paleotemperatures and other hydrological parameters deduced from gases dissolved in groundwaters, Jordan Rift Valley, Israel. Geochem. Cosmochim. Acta 36, 1321-1336 (1972).

2. Andrews, J. N. \& Lee, D. J. Inert gases in groundwater from the Bunter Sandstone of England as indicators of age and palaeodimatic trends. J. Fyydrot. 41, 233-252 (1979).

3. Stute, M. \& S Schlosser, P. in Climate Change in Continental Isotopic Records (eds Swart, P. K., Lohmann K. C., McKenzie, J. \& Savin, S.) 89-100 (American Geophysical Union, Washington DC, 1993).

4. Stute, M. et at Cooling of tropical Brazil $\left(5^{\circ} \mathrm{C}\right)$ during the Last Glacial Maximum. Science 269, 379 383 (1995).

5. Beyerle, U. et at. Cimate and groun dwater recharge during the last glaciation in an ice-covered region. Science $282,731-734$ (1998)

6. Weyhenmeyer, C. E. et at Cool glacial temperatures and changes in moisture souroe reoorded in Oman groundwaters. Science 287, 842-845 (2000).

7. Stute, M. \& Schlosser, P. in Environmental Tracers in Stbbsurface Hydrotogy (eds Cook, P. \& Herczeg, A. L.) 349-377 (Kluwer Academic, Boston, 2000)

8. Heaton, T. H. E. \& Vogel, J. C. "Excess air" in groundwater. J. Hydrot 50, 201-216 (1981).

9. Ballentine, C. J. \& Hall, C. M. An inverse technique for calculating paleotemper atures and other variables using noble gas concentrations in groundwater. Geochim. Cosmochim. Acta 63, 2315-2336 (1999).

10. Christiansen, J. E. Effect of entrapped air upon the permeability of soils. Soit Sci. 58, 355-365 (1944).

11. Fayer, M. J. \& Hillel, D. Air encapsulation: 1. Measurement in a field soil. Soit Sci. Soc. Am. J. 50, 568$572(1986)$.

12. Faybishenko, B. A. Hydraulic behavior of quasi-saturated soils in the presence of entrapped air Laboratory experiments. Wat. Resoter. Res. 31, 2421-2435 (1995).

13. Lehmann, B. E. \& Purtschert, R. Radioisotope dynamics - the origin and fate of nuclides in groundwater. Appt. Geochem. 12, 727-738 (1997).

14. Schlosser, P., Stute, M. Sonntas, C. \& Münnich, K. O. Tritiogenic ${ }^{3} \mathrm{He}$ in shallow groundwater. Earth Planet. Sci. Lett. 94, 245-256 (1989).

15. Aeschbach-Hertig, W. et at. $\mathrm{A}^{3} \mathrm{H} /{ }^{3} \mathrm{He}$ study of ground water flow in a fractured bedrock aquifer. Ground Wat. 36, 661-670 (1998)

16. Dunkle Shapiro, S., Rowe, G., Schlosser, R., Ludin, A. \& Stute, M. Tritium-helium 3 dating under complex conditions in hydraulically stressed areas of a buried-valley aquifer. Wart. Resour. Res. 34 $1165-1180$ (1998).

17. Beyerle, U. et at. Infiltr ation of river water to a shallow aquifer investigated with ${ }^{3} \mathrm{H} /{ }^{3} \mathrm{He}$, noble gases and CFCs. J. Fydrot. 220, 169-185 (1999).

8. Solomon, D. K., Hunt, A. \& Poreda, R. J. Source of radiogenic helium 4 in shallow aquifers: Implications for dating young groundwater. Wat. Resour. Res. 32, 1805-1813 (1996).

19. Osenbrück, K., Lippmann, J. \& Sonntag, C. Dating very old pore waters in impermeable rocks by noble gas isotopes. Geochim. Cosmochim. Acta 62, 3041-3045 (1998).

20. Heaton, T. H. E., Talma, A. S. \& Vogel, J. C. Origin and history of nitrate in confined groundwater in the western Kalahari. J. Fydrot. 62, 243-262 (1983).

21. Wilson, G. B. \& McNeill, G. W. Noble gas recharge temperatures and the excess air component. Appt. Geochem. 12, 747-762 (1997).

22. Stute, M. \& Talma, A. S. in Isotope Technigutes in the Study of Environmental Change 307-318 (IAEA, Vienna, Austria, 1998).

23. Aeschbach-Hertig, W., Peeters, E, Beyerle, U. \& Kipfer, R. Interpretation of dissolved atmospheric noble gases in natural waters. Wat. Resokr. Res. 35, 2779-2792 (1999).

24. Aeschbach-Hertig, W., Stute, M., Schlosser, R., Clark, J. \& Reuter, R. Large $\left(9^{\circ} \mathrm{C}\right)$ glacial-inter cha cial temperature difference derived from an aquifer in Maryland (abstr.). Eos 77, (Supp1) S157 (1996) 5. Mamyrin, B. A. \& Tolstikhin, L. N. Hetium Isotopes in Native (Elsevier, Amsterdam, 1984).

26. CLIMAP. The surface of the ice-age Earth. Science 191, 1131-1137 (1976). 
27. Rostek, E. et al. Reconstructing sea surface temperature and salinity using $\delta^{18} \mathrm{O}$ and alkenone records. Nature 364, 319-321 (1993).

28. Rind, D. \& Peteet, D. Terrestrial conditions at the last glacial maximum and CLLMAP sea-surface temperature estimates: Are they consistent? Quat. Res. 24, 1-22 (1985).

29. Thompson, L. G. et al. Late glacial stage and holocene tropical ice core recor ds from Huascatán, Pero. Science 269, 46-50 (1995).

30. Benson, B. B. \& Krause, D. Isotopic fractionation of helium during solution: A probe for the liquid state. J. Solict. Chem. 9, 895-909 (1980).

\section{Acknowledgements}

We thank $\mathrm{J}$. Holocher and H. Baur for help in the laboratory and for discussions, and M. Stute, R. Reuter, K. Walraevens, I. Lermytte and C. Weyhenmeyer for collaboration in the field studies.

Correspondence and requests for materials should be addressed to W.A.

(e-mail: aeschbach@eawag.ch). 